management, machine learning, and distributed computing with massively parallel processing. They used 90 high-powered servers and 10 refrigerator-sized racks for the machine. And they proved that Watson could win over the two previous biggest winners on Jeopardy. As a result, Watson captured the imagination of a wide audience.

Since then, IBM has made many enhancements to make the system practical in the real world. It is now 240 percent faster, only requires one rack of equipment, and can accept multi-dimensional input. Health care is their first area of interest. He pointed out that there are 95 new clinical trials launched every day and that medical information, much of which is unstructured, is doubling every five years. Yet, 81 percent of physicians report that they spend five hours or less per month reading medical journals! This is an area in which Watson can play a significant role. Their first product launch is in collaboration with the Sloan Kettering Clinic and will be focused on cancer treatments-specifically lung, breast, prostate, and colorectal cancers. They are also in discussions with organizations both in the financial and scientific arenas. Stein closed by saying that we are now in an era of being able to build knowledge through cognitive computing.

Everyone at the conference agreed that the combination of Big Data and technology is a major catalyst in the advancement of research and knowledge. To quote the authors of the book mentioned earlier in this report, ". . . the new techniques for collecting and analyzing huge bodies of data will help us make sense of our world in ways we are just starting to appreciate."

http://nfais.org/event?eventID=399

\section{Science for Poverty Eradication and Sustainable Development}

\section{by Javier Garcia Martinez}

Imagine having the opportunity to speak to the presidents of the national science academies of the entire world. What would you tell them? What brilliant idea might you share to solve our most urgent problems?

Trying to answer these critical questions is what a group of 134 leading scientists, some of them presidents of national science academies themselves, did from 25-27 February 2013 in Rio, Brazil (i.e., the same city where the Earth Summit (1992) and Rio+20 (2012) were held). Far from being an academic and formal meeting, the presidents of the science academies engaged in very vivid discussions using the Challenge Labs method, a format frequently used in the Davos meetings. In Challenge Labs, young scientists, many of them members of the Global Young Academy, moderate and provoke conversations on topics of great relevance, such as global heath, clean water access, universal science literacy, clean energy production, or food security. It was really refreshing seeing leading international scientists and academicians from prestigious organizations gather around flip boards to passionately discuss how science can provide specific solutions to real problems.

One of the goals of the science academies meeting was to identify and propose solutions to our new development goals. The original ones, the Millennium Development Goals (www.un.org/millenniumgoals), were signed by nearly all nations in 2000 and will expire in less than three years, in 2015 . They are mainly related to poverty and its causes and consequences. For this reason, the Conference and General Assembly of the Global Network of Science Academies in Rio met under the theme: "Grand Challenges and Integrated Innovations: Science for Poverty Eradication and Sustainable Development."

The structure of the meeting was quite interesting. Instead of the typical large plenary sessions and reports from the different academies, the first day of the meeting was structured around Challenge Labs, a concept developed by the World Economic Forum to first present different topics, then discuss them in small groups, and finally report on them to the bigger group. Among the issues discussed in the were those that one would expect: health, energy, water, food security... although the one that attracted more interest was science literacy. There was a wide consensus on the importance of understanding the fundamentals of our global challenges as the first step toward solving them.

The first day of the meeting was led by members of the Global Young Academy, the new constituent of the InterAcademy Panel, formed from young scientists from all around the world, in clear contrast with the traditional national science academies. The second day was centered around the new Science Agenda and Future We Want. Several panels, based on the same format used in Davos, with very short presentations followed by questions from the public, were held to discuss critical topics, such as ethics, science 
literacy, food security, and renewable energy sources. The result was a clear call to translate scientific results into improving the quality of life of those in need and inspiring the best minds to solve our common and urgent challenges.

Panel discussions were also part of a very full and diverse program that covered topics such as "The Role of Science in Coping with the Grand Challenges Facing Humanity," "Poverty Eradication and Sustainable Development," and "Grand Challenges and Integrated Innovation: Lessons from the Experience."

To make sure that all the ideas, proposals, and projects that come out of the discussions in Rio could see the light of reality, several funding agencies such as USAID, the Bill \& Melinda Gates Foundation, and Grand Challenges Canada were present at the meeting and were actively involved in the discussions. In fact, during the lunches, several meetings were conducted between those who had just thought of a new project and potential funding agencies, which provided quick feedback on the possibilities of such a project.

One of the conclusions of the meeting was to create a website that will allow collecting ideas from people about priorities, best activities, and solutions regarding our most pressing challenges. This is your opportunity to tell the presidents of the national science academies about your brilliant idea to solve global problems. Think carefully, we all may rely on it.

The role of chemistry in providing very specific solutions to many of the challenges discussed was very clear during the deliberations held at the conference, from better materials for clean energy production to more effective drugs to treat wide-spread illnesses, such as malaria, AIDS, or tuberculosis. The positive role of chemistry in providing clean, safe water and the need to increase food security was also mentioned in several of the panels and challenge labs. Participants agreed that climate change, which was

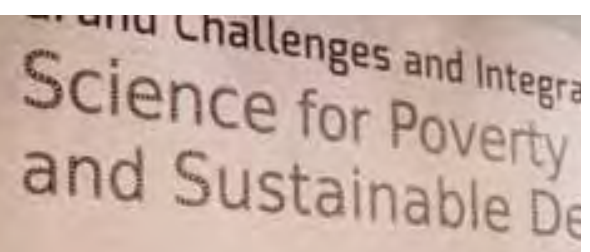

Javier Garcia Martinez addresses representatives

of the National Science Academies on the role of chemistry in a sustainable energy future. discussed on several occasions, was a main challenge for which better science in general, and chemistry in particular, is desperately needed.

What better inspiration for the new generation of scientists than to contribute to improving the lives of those in poverty? Following the footsteps of those great chemists who invented the solutions that make us healthier and able to enjoy life in so many ways, from penicillin to fertilizers, from clean water to vaccines, a new generation of chemists are critical to providing the solutions we need for a planet with 7-billion people. As President John F. Kennedy said at the American University in Washington, D.C., in 1963, "Our problems are man-made, therefore they may be solved by man. No problem of human destiny is beyond human beings." And science is the most (some would say the only) tool that men (and women) have to find the solutions to those problems.

Online References

www.interacademies.net/Activities/10880/BAS2013.aspx www.thechemicalelement.com/

www.wiley.com/WileyCDA/WileyTitle/productCd-3527328807. html

www.iupac.org/publications/ci/2012/3402/bw.html

www.chemistryviews.org/details/book/878409/The_ Chemical_Element_Chemistrys_Contribution_to_Our_ Global_Future.html

www.chemistryviews.org/details/ezine/2043175/The_ Chemical_Element.html

www.chemistryviews.org/details/ezine/1077239/Will_ Chemistry_Make_the_World_a_Better_Place.html

The Letter from Rio-2013-the output of the IAP Conferenceis available as one resource document online at www.interacademies.net/20197.aspx

\section{Advanced Polymeric Materials}

\section{by Byung-Wook Jo and Michael Hess}

The IUPAC-sponsored World Forum on Advanced Polymeric Materials, POLYCHAR 21, was held in March 2013 in Gwangju, South Korea. Founded in 1992, POLYCHAR had been held annually at the University of North Texas, Denton, until 2004 when it was held in Portugal, the first POLYCHAR held outside the USA. Since then, it has been held in Singapore (2005), Japan (2006), Brazil (2007), India (2008), France (2009), Germany (2010), Nepal (2011), and Croatia (2012). 